\title{
DESIGN REQUIREMENTS TO EDUCATE AND FACILITATE JUNIOR DESIGN PROFESSIONALS TO REFLECT MORE EFFECTIVELY ON CRITICAL SITUATIONS AND CONFLICTS AT WORK
}

\author{
Onselen, Lenny van (1,2); De Lille, Christine (1,2); Snelders, Dirk (2) \\ 1: The Hague University of Applied Sciences; 2: Delft University of Technology
}

\begin{abstract}
Junior designers are not trained to cope with critical situations and conflict at work. Most design schools do not educate their design students to prepare them for (potential) conflict. As a result, junior designers often do not have conflict-handling skills to handle critical situations and conflicts. While some tools and methods exist to help them make responsible design choices, these often address value differences underlying (potential) conflict without taking the perspective of the designer, and thus without supporting young designers to start by reflecting on their own intrinsic values.

The aim of this study is to find a way to help junior designers to reflect effectively on critical situations, thereby improving their conflict-handling skills. Data was collected through four steps in an action research. Researchers collaborated with an identity programme for junior design professionals. Insights from try-outs and small interventions were transferred into design requirements for an approach to educate and facilitate junior design professionals to reflect more effectively on critical situations.
\end{abstract}

Keywords: Design practice, Collaborative design, Design education, Reflection, Value-based conflicts

Contact:

van Onselen, Lenny

The Hague University of Applied Sciences

Faculty of Technology, Innovation and Society

The Netherlands

l.vanonselen@hhs.nl

Cite this article: Onselen, L., De Lille, C., Snelders, D. (2019) 'Design Requirements to Educate and Facilitate Junior Design Professionals to Reflect more Effectively on Critical Situations and Conflicts at Work', in Proceedings of the 22nd International Conference on Engineering Design (ICED19), Delft, The Netherlands, 5-8 August 2019. DOI:10.1017/ dsi.2019.331 


\section{INTRODUCTION}

If we want future designers to act responsibly, they have to be aware of values. In the last decade, scholars have developed tools to integrate values of users (Friedman and Hendry, 2012) and societal stakeholders (den Ouden, 2012). Designers can use values-led design tools to make responsible design choices. However, in order to stay motivated in developing such choices, they have to follow intrinsic values, i.e., growth oriented and anxiety free values sprouting from basic psychological needs (Kasser and Ahuvia, 2002; Schwartz, 2012).

Young designers are hired for fresh ideas. Nonetheless, they frequently experience value differences with clients, co-workers and other stakeholders when they bring these ideas to the table. Scholars suggest peer pressure and incongruent values can hinder performance (Jehn et al., 1997), work engagement (Sortheix et al., 2013), well-being (Sheldon and Kasser, 2001), creativity and innovation (Rothkegel, 2012), and value differences might turn into conflicts. Seasoned professionals cope with (potential) value-based conflicts with conflict handling skills (Arnold, 2002; Clark, 1997; Schön, 1983). In a prior study, we learned that the experience of value-based conflicts is key in becoming a design professional. Yet, it became also clear that time and energy can be wasted in developing such skills without support.

Values can be defined as social principles, which designers can evaluate as more or less personally meaningful (Boradkar, 2010; Le Dantec and Do, 2009). Value differences occur when values oppose or compete with one another (Schwartz, 2012), for example quality versus costs. When people hold different values and find different solutions to solve these differences, conflicts in collaboration emerge (Lynn Fitzpatrick, 2007). Conflicts are defined as: disagreement, interference, or negative emotions following the typology of Barki \& Hartwick (2004).

In a prior study we have identified critical situations or events in collaborative design practice where value differences come to the surface, for example a discussion in a design team about the quality versus the cost price of the product. Value-based conflicts arise from such critical situations. Such conflicts are often anxiety-based, and they may block intrinsically held values, preventing junior design professionals to grow and be motivated for their work. Value-based conflicts can consist of fighting, disagreements, interferences or even fierce emotional experiences. Such conflicts are often destructive, especially for junior designers at the beginning of a professional career (and sometimes already as a student during internships) when inexperience leads to a poor handling of value differences, critical situations and resulting conflicts.

Support might be improved for junior design professionals to better cope with critical situations. As a case in point, the first author experienced a value-based conflict as a junior freelance design consultant. She sought support from coaches and books, and invested in professional development courses. Although some of these support tools where tailored to engineers or start-up companies, none grasped the essence of what design professionals need. Only recently, design identity courses and personal branding books for creative professionals provide some support to junior designers. Still, most junior designers are unprepared for critical situations at work based on value differences, and design schools do not prepare students.

If junior designers are more aware of value differences and possible critical situations and know how to identify and reflect on them, they could avoid unintended behaviour, negative emotions (Malle, 2004), and destructive value-based conflicts. They can act with purpose and come to grips with valuebased conflicts, solving value differences in a more integrative and constructive way. In this article, we describe the first steps of an action research. Based on the insights from the study, we have formulated requirements to educate and to facilitate junior design professionals to improve reflection on critical situations at work based on value differences.

\section{RESEARCH APPROACH}

The aim of this study is to find ways to facilitate junior designers to reflect effectively on critical situations to improve the way they handle value differences, critical situations, and value-based conflicts, to support the process of professional development. Action research is of qualitative nature and aims to produce useful results which fits our goal to develop support for junior design professionals. Through action research better understanding of a situation is acquired while simultaneously the situation is changed (Blessing \& Chakrabarti, 2009; Bradbury Huang, 2010). In 
this action research, we had a unique chance to collaborate with a designer's identity programme while it was running. The goal was to support reflection on value differences, critical situations, and valuebased conflicts. We have studied ten junior design professionals with no more than two years of work experience. We have collected insights through small experiential interventions which we called tryouts. We tested or tried out learning activities to increase awareness, support reflection, and develop coping strategies. At the same time we aimed to formulate design requirements for an educational approach and support tools. Data was collected through four steps in action research. Table 1 describes per action step the research activity, the involved participants, the setting of the activity, the gathered data, and the resources and the stimuli used.

Table 1. Action steps in the research

\begin{tabular}{|c|c|c|c|c|}
\hline Action step & Participants & Setting & Data & $\begin{array}{r}\text { Resources \& } \\
\text { stimuli }\end{array}$ \\
\hline $\begin{array}{l}\text { 1. Meeting the academy: } \\
\text { visit exhibition of trainees } \\
\text { and brainstorm ideas for } \\
\text { future collaboration }\end{array}$ & $\begin{array}{c}10(\text { all }) \\
\text { trainees } \\
1 \text { coordinator } \\
3 \text { coaches }\end{array}$ & $\begin{array}{l}\text { Creative hub in old } \\
\text { factory, } 2 \text { hour visit } \\
\text { during presentation }\end{array}$ & $\begin{array}{l}\text { Observation } \\
\text { notes, } \\
\text { photographs, } \\
\text { video material }\end{array}$ & $\begin{array}{r}\text { Education } \\
\text { development } \\
\text { experience of } \\
\text { coordinator and } \\
\text { coaches }\end{array}$ \\
\hline $\begin{array}{l}\text { 2. Coach interventions in CS: } \\
\text { trainees worked on a client } \\
\text { project }\end{array}$ & $\begin{array}{l}10 \text { trainees } \\
1 \text { coordinator } \\
3 \text { coaches } \\
2 \text { clients }\end{array}$ & $\begin{array}{l}\text { Creative hub in old } \\
\text { factory, } 2 \text { weeks, } 3 \\
\text { half day meet-ups }\end{array}$ & $\begin{array}{l}\text { Observation } \\
\text { notes, } \\
\text { presentation } \\
\text { recording }\end{array}$ & $\begin{array}{r}\text { Pedagogical } \\
\text { experience of } \\
\text { coordinator and } \\
\text { coaches }\end{array}$ \\
\hline $\begin{array}{l}\text { 3. Insights talks: trainees } \\
\text { gain insight in experienced } \\
\text { critical situations }\end{array}$ & $\begin{array}{l}6(\text { of } 10) \\
\text { trainees } \\
1 \text { coach }\end{array}$ & $\begin{array}{l}\text { Abandoned office } \\
\text { building, } 2 \text { weeks, } \\
\text { preparations } \\
\text { exhibition }\end{array}$ & $\begin{array}{l}\text { Recordings, } \\
\text { transcriptions, } \\
\text { diagrams, } \\
\text { exercises, } \\
\text { notes }\end{array}$ & $\begin{array}{r}\text { Coaching guide, } \\
\text { value-based } \\
\text { conflicts } \\
\text { overview, } \\
\text { sensitizing } \\
\text { exercises }\end{array}$ \\
\hline $\begin{array}{l}\text { 4. Observing junior design } \\
\text { professionals: trainees } \\
\text { worked on an exhibition of } \\
\text { their portfolio and identity }\end{array}$ & $\begin{array}{l}10 \text { trainees } \\
1 \text { coordinator } \\
3 \text { coaches } \\
2 \text { clients }\end{array}$ & $\begin{array}{l}\text { Creative hub in old } \\
\text { factory, } 2 \text { weeks, } 3 \\
\text { half day meet-ups }\end{array}$ & $\begin{array}{l}\text { Observation } \\
\text { notes, } \\
\text { presentation } \\
\text { recording }\end{array}$ & $\begin{array}{r}\text { Pedagogical } \\
\text { experience of } \\
\text { coordinator and } \\
\text { coaches }\end{array}$ \\
\hline
\end{tabular}

\subsection{Context: Designer's Identity programme (DI)}

The Fundamentals Academy offered various design programmes for junior designers, such as the Designer's Identity programme (DI). This programme supported recently graduated designers in a reflection-year. It started with a full-time programme for 3 months with workshops, client projects, and a war room event. The following half year, trainees continued their own career paths, with regular meetings, workshops, and a final expo. The first run of the programme was in 2017. Ten junior professionals participated as trainees in this programme (trainee 1 , trainee 2 , etc.). They either had a background in design or an interest for what design could contribute to their professional mindset. The trainees signed consent to use the data gathered about them anonymously. The programme was developed and organized by the coordinator. Coaches tutored the trainees on individual development or in groups during client projects or programme activities (coach 1,2 and 3). A client project is a real case design assignment brought in a by an external company client. In this case, the company client was a large retail company represented by 2 employees (client 1 and client 2). The first author was a coach in the programme and kept a research journal and was involved in all four action steps (coach 1).

\section{FACILITATING REFELCTION}

Drawing from the action research, we will describe four findings that led to the main requirements to facilitate reflection on value differences, critical situations, and value-based conflicts. Our starting point was a prior study from which we derived four requirements: 
- Raise awareness of value differences: often designers are not aware that frustrations or conflicts may be based on value differences. Making them aware of this will help them cope sooner and more effectively.

- Illustration of critical situations: designers are visually minded professionals, so if exercises or supportive tools includes visuals it will help most design professional to better understand critical situations.

- $\quad$ Rich exemplary narratives: not losing depth of examples shown during workshops or visualised in a tool.

- Comprehensible methods: easy to understand tools.

First, we describe interventions taken by coaches in critical situations during a client project (section 3.1). Secondly, we further explore insight talks (structured coaching conversations) that might be useful for facilitated reflection (section 3.2). Finally, we propose and discuss an exercise of visual reflection (section 3.3). Figure 1 shows the timeline of the DI programme with the actions taken: (1) meeting the academy, (2) coach interventions, (3) insights talks, and (4) observing junior professionals.

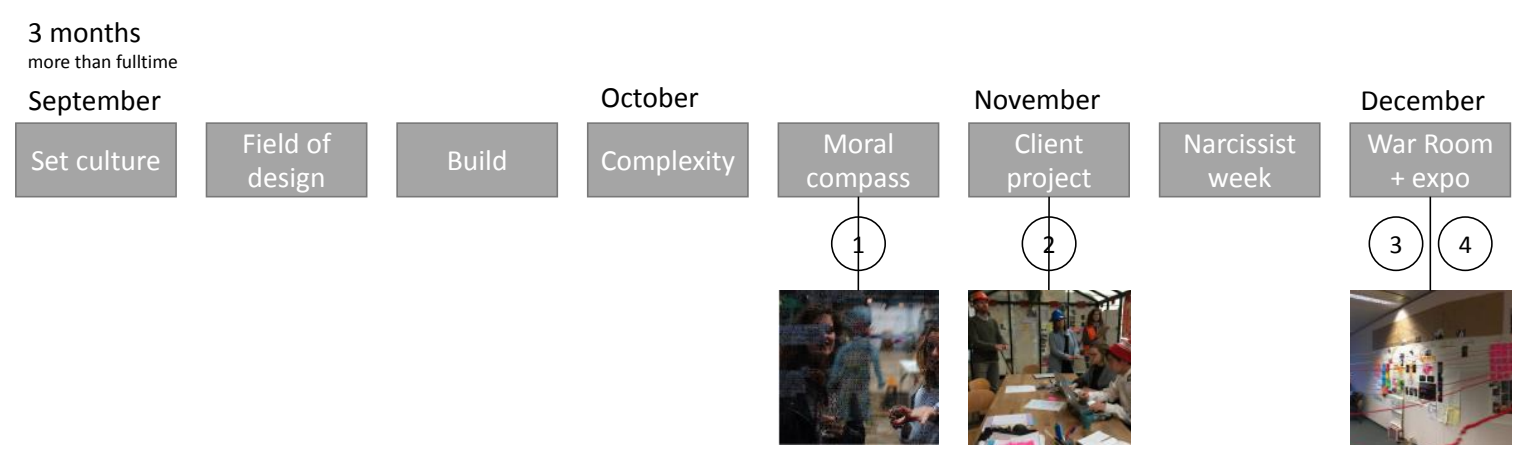

Figure 1. DI timeline with the four action steps

\subsection{Try-out: coach interventions in critical situations}

In action step 1 and action step 2 of this study, we observed four distinct critical situations. We will describe the critical situations, how the trainees dealt with them, and how the coaches intervened.

\subsubsection{A product development discussion}

The first critical situation occurred on the first day during the client's kick-off. All of the trainees were involved, referred to as the group. Three coaches (including the first author), client 1 and the coordinator were present. A first notion of the critical situation was seen when trainee 1 wanted to present an idea. Client 1 said "I need to play the devil's advocate." Client 1 explained it was important to have a sound business case, stating his values clearly.

"Immediately after the client's presentation, I observed the first critical situation. It was a product development discussion between the client and the group. A difference in views on commercial relevance and social impact." [Note from the research journal]

A discussion started when client 1 left. The group split into two parties. One half was in favour listening literally to the client's wishes. The other half supported a more innovative and impactful design approach.

"The coordinator asked the group what their thoughts where. What makes them twerk about this assignment and what are their concerns.[...] The dilemmas of the group are: costs/revenue versus social impact - qualitative versus quantitative. The coordinator explained that he primed the client that the group could not be quantitative. Articulate what is different? How to get this across? Make it realistic and what has the highest chance of having it in the store?" [Note from the research journal] 


\subsubsection{The ambition choice}

The second critical situation was observed a few days after the kick-off. The group was working on the project. Ongoing discussions stood in the way of productive teamwork. Eight of the trainees were involved in the discussion. The coordinator and coach 1 were present to guide the group. The trainees thought of dividing up roles to smoothen their design process in the project. Most roles were taken up easily, except for the team leader role. A second critical situation was observed: the ambition choice which is a dilemma of becoming a manager or an expert designer. Some trainees shared they had taken up team leader roles in the past. Now, however, they preferred to focus on developing their skill as a designer. The discussion who to assign as team leader went on for about half an hour. The coordinator and coach 1 followed the discussion and facilitated them to make a decision. The coordinator and coach 1 did not make resolute interventions as the trainees seemed to handle the situation quite well.

\subsubsection{Lacking acknowledgement and a creative frustration}

The third and fourth example of critical situation occurred simultaneously and turned into value-based conflicts. All trainees were present of which three were involved directly in the value-based conflicts. Coach 1 and coach 2 and the coordinator were present. After a week of hard work, trainee 2, 3 and 4, led client 1 and client 2 through a carefully prepared presentation. The rest of the group continued working on the project aside from the presentation.

Client 1 responded after the three trainees presented the work. Client 1 said "if this was a real assignment." Client 1 also shared new constraints to the assignment. Additionally, client 1 said the trainees were "training to be professionals", treating them as students or non-professionals. The frustration could be read from their faces.

"After the client went off with the programme coordinator to discuss details, trainee 2 asked: was it me or was this strange? I told trainee 2 that he was not wrong at all." [Note from the research journal]

Coach 2 joined the conversation between coach 1 and trainee 2,3 and 4 to share that he felt the comments of client 1 were inappropriate. The coaches in the programme referred to the trainees as professionals further developing themselves, and never as students. Not acknowledging their professionalism was a slap in the face for the three trainees. The new constraints seem to be a creative frustration for trainee 2 . We decided to wait until both clients left the building before sharing the incident with whole group and reflect on it.

"I sat with the group all the time and noticed agitation and tension. Some made jokes which where appeased by others. " [Note from the research journal]

Client 2 left, while client 1 and the coordinator came back in the room where the group was working. The coordinator presented all the work to client 1 one more time. This presentation lasted for more than half an hour, while the group continued with the project.

"The atmosphere was tense and surprised glances where shared among the trainees. Maybe they felt offended." [Note from the research journal]

When client 1 eventually left, trainee 3 shared in the group what happened. Trainee 2 stood silent outside the group and seemed frustrated. Trainee 4 already found a way to cope with the conflict. Trainee 4 turned the client comments into new opportunities and ideas. Encouraged by the coaches, trainee 2 explained the new constraints frustrated him. Trainee 2 believed client 1 should have made this clear at the start of the project. Another trainee from the group, trainee 5, said it could also be their own mistake not to ask this during the kick-off. Trainee 5 suggested to find possibilities and wanted to know how they could change concepts into new concepts fitting the new constraints.

\subsubsection{Requirements for reflection}

While we observed the critical situations, coaches were able to intervene when needed. Intervention is aimed at building a relationship to help out (Agyris and Schön, 1978). We noticed trainees who experienced critical situations had sometimes difficulties to cope with them effectively right away. In the moment itself, they dealt with the situation calmly, acting in a way they felt professionals would do. Yet, shortly after the incident, negative anxiety-based emotions emerged. They felt frustrated, unacknowledged, or insecure. Some trainees coped with the situation by turning the frustration into something useful or productive through a quick reflection-on-action. This resulted in a change of perspective on the critical situation. Others remained longer in negative emotions. Short dialogues with different coaches and a team reflection helped to find a way to cope with the situation. 
Supporting reflection in these situations might benefit the designer who is stuck in a negative emotion. To support designers reflect effectively and help transfer the negative emotion into a productive coping strategy would increase productivity and well-being. To summarize, design criteria for the reflection approach emerging from action steps 1 and 2 were:

- Quick reflection-on-action: stimulate reflection shortly after a critical situation. Use short coaching dialogues to change perspective and find solutions to the problem.

- Prepare to reflect skilfully: increase a junior designers' competence to reflect on critical situations and value-based conflicts.

\subsection{Try-out: insights talks}

In our prior study, we noticed that the interview facilitated reflection on professional development. These interviews supported learning and insights emerged on how to cope (better) with critical situations. The goal of this try-out was to transform the reflective interviews into coach interventions. In our try-out the interviews or coaching talks were neither solely reflective nor entirely intervening, we therefore called them insights talks. In the role of coach, the first author had 5 insights talks in the weeks leading up to the expo of their designer identity (action step 3) and one shortly after the expo (action step 4). The insight talks gave the trainees a deeper understanding of their identity through an exploration of experienced value-based conflicts. We collected three considerations applicable to these insight talks:

- The interview guide developed in the prior study worked best to reflect on past events.

- Designers easily recognize value differences of others, and they can link them with their own experiences. The associated cases do not always belong to the same category, but they are useful for reflection and learning.

- Preparation exercises give designers the best mindset for their talk.

\subsubsection{The coaching guide}

One goal of this try-out was to transfer the interview guide of our prior study to a guide supporting intervention. The coaching guide was adjusted slightly before and over the course of the insights talks. The topics addressed in insights talks 1 and 2 were: work experience \& collaboration, personal values \& motivation, reflect on value differences, and review of case examples. The guide provided reverence and the talk went its own course where needed. Topics were added for insights talks 3, 4 and 5. Firstly, the trainees were asked to place the value differences in their war room timeline. Secondly, the participants were asked at the end of the insights talks if there was a topic they wanted to dive into with the coach. Topics they mentioned were: their values (3), background of the coach (3 and 5), and feedback on designer identity (4). These topics could be added to the conversation guide.

\subsubsection{Stimuli as support tools}

In the insights talks, four forms of stimuli were used: an overview of value differences, critical situations, conflict categories, and relation diagrams of cases experienced by design professionals. The relation diagrams are drawings representing the value-based conflicts in a visual way. Through trial and error we explored how to use the stimuli most effectively as support tools in the insights talks.

In insights talks 1, the overview of value differences was used to discuss the topic personal values, however, this took too much time away from the rest of the insights talks. In insights talks 2, the overview was introduced for reviewing case examples. However, in the overview some words were not self-explanatory.

The relation diagrams of interview cases of our prior study (see Figure 2) did not work well during the first three insight talks, so it was taken out of insights talks 4 and 5. The relation diagrams needed a better introduction on how to read them. In insights talks 6 , the relation diagrams were used again, but now specifically for giving advice on how to cope with a situation. The relation diagrams need more development or added information to be self-explanatory support tool. Also in this insights talks, the overview of value differences was used to compare the trainee's experience with cases of others and learn from this comparison. 


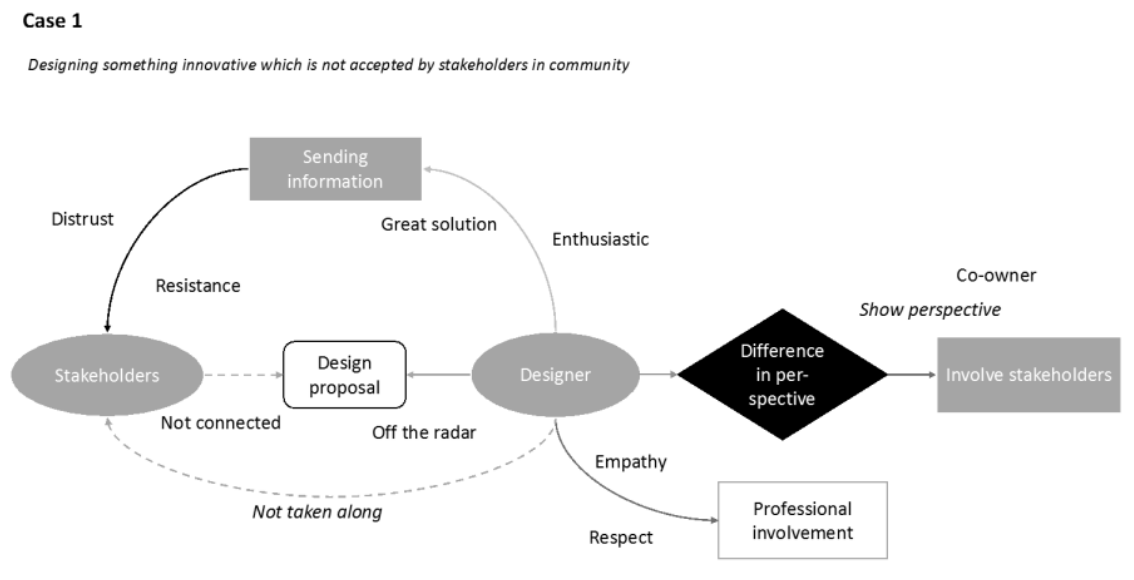

Figure 2. Example of a relation diagram

\subsubsection{Sensitizing exercises as support tools}

The participants were sensitized to get a feeling of the insights talks goals and topics and connect it to their own experiences (Stappers \& Sanders, 2012 p.157). It allows them to prepare and to share their critical situation during the insights talks. We primed the participants of this study before the insights talks with a preparation survey. The survey contained three exercises with questions based on the topic guide: work experience \& collaboration, personal values \& motivation, and reflect on value differences. The questions were inspired by the Intragroup Conflict Scale (Jehn, 1995) which measures relationship conflicts. Additionally, we asked them to visualize their critical situations on paper without constraints.

Trainees of insights talks 2 and 5 were enthusiastic about the preparation exercise and suggested to give more exercises upfront. For example, an exercise to uncover their values. The trainee of insights talk 6 added more material on his own initiative. He shared insights from his war room exploration and coaching talks, which he believed to be relevant for our meeting. He sorted the insights into four categories: positive points, things that need work, helpful, and hindrances. He also added a mind map about how he wanted to position himself as a designer.

\subsubsection{Requirements for insights talks}

The coaching guide and the sensitizing exercises can already be used for reflecting on value-based conflicts and designer identity. Yet, the guide and exercises need further development, if to be used as intervention method. We assumed the trainees would share their recent experiences during the insights talks, for example those observed in the weeks before (see section 3.1). However, most critical situations they shared occurred before the DI programme. Some shared cases of critical situations which happened during the DI programme, but not the three we have observed (see section 3.1). Possibly the critical situations shared were more important for their professional identity. And perhaps the small interventions we did as coaches were helpful enough to address the critical situations while present. In sum, design criteria gathered are:

- Develop insights talks and stimuli: give deeper insights on designers' identity based on the valuebased conflicts they experienced. Discuss topics such as work experience, collaboration, personal values, motivation, reflect on value differences, and review case examples. Use stimuli to increase awareness and facilitate reflection.

- Facilitate professionalization reflection and insight: the overview of value differences, critical situations, and conflict categories will generate all kinds of associations with own experiences. It will lead to a broad understanding and awareness of how value-based conflicts influenced their professionalization.

- Share comparable cases: similar cases and coping strategies can offer coaches a tool to give advice to cope with value-based conflicts

- Define an intervention motive: the reason to have an insights talk should be a conflict, so an intervention can take place. Otherwise they will only share conflicts from the past.

- Reflect in context: give reflection activities or sensitizing assignments in the context of the designer, it allows to refer and embody the experience. 
- Give sensitizing activities: send sensitizing exercises before coach meetings or interventions. Stimulate to add information of their own picking that is related to professional development.

- Build a sensitizing toolkit: four or five sensitizing assignments (e.g. to uncover values) from which a facilitator can select most appropriate.

\subsection{Try-out: visual reflection}

Designers are in general well trained visual thinkers and familiar with solving problems through analogy (Casakin and Goldschmidt, 1999). They may reach deep reflection while visualizing critical situations on paper. The sketches resulting from visual reflection could serve as boundary objects useful for sharing the critical situation with the coach or team (Akkerman and Bakker, 2011; Carlile, 2002). Moon (1999, p.206) states many visualization exercises exist that are reflective and may support learning. Unfortunately, Moon (1990) does not give concrete examples of visual reflection exercises.

We observed in the action step 3 how designers visualize critical situations in different ways (see Figure 3). During the insights talk the participant can explain the drawing. As response to the sensitizing assignment we received different ways of drawing depending on the skill of the designer. For example, one participant send an illustration in a style she uses in her own business as her signature mark. One other participant chose to visualize his critical situation in a simple scheme.

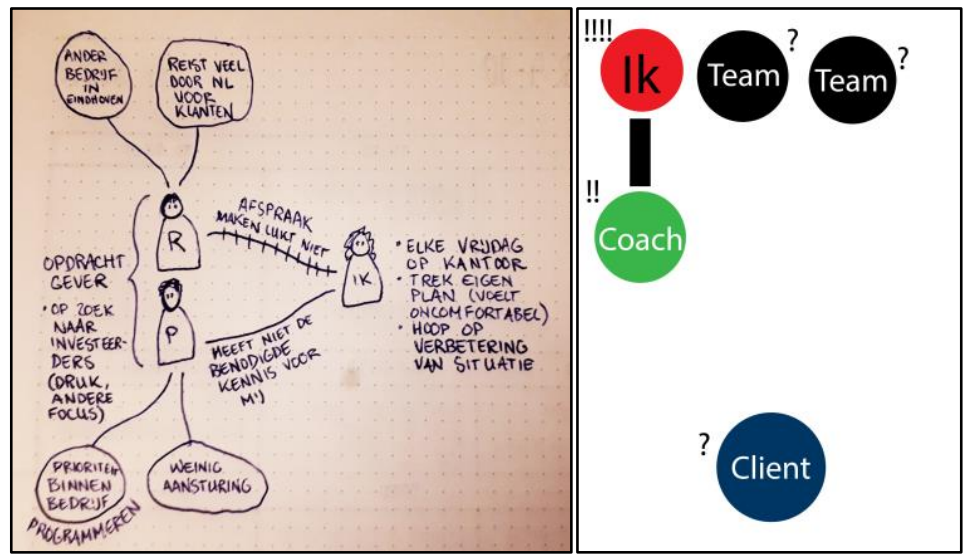

Figure 3. Two visualizations of a conflict as preparation for an insight talk

When visual reflection is done in a group, the type of visual may be prescribed. Especially, if the drawing is also used for plenary presentation. Metaphors and story cartoons might be suitable for visual reflection in group sessions as are easy to understand and are self-explanatory when shared plenary.

\subsubsection{Requirements for visual reflection}

Although the visualization of critical situations needs further development, for now we come to the following criteria for the concept approach:

- Add a sketching assignment in sensitizing toolkit: include specific sketching assignments in sensitizing without prescribing the type of visual reflection.

- Prescribe metaphor or story cartoon as sketching assignment: in group visual reflection include a sketching task in the workshop description. Metaphor or story cartoon came forward as most useful when the visual is also used for plenary presentation.

\section{CONCLUSION AND FURTHER RESEARCH}

In this action research study, we have collected insights through small interventions in critical situations, insight talks, and analysis of visual reflection. These insights were transformed into design requirements for an approach to provide insight and facilitate reflection. Currently, we are working on a first concept of an approach to educate and facilitate junior designers to improve reflection on critical situations. We have formulated initial ideas for learning activities in the concept approach, but more exploration of literature and practice is needed to formulate a set of activities fitting the requirements and needs of the target group. Future research should evaluate this concept approach 
based on the design requirements. As part of this approach, support tools and facilitation toolkits may be developed and tested to support education and facilitation of junior designers.

\section{REFERENCES}

Agyris, C. and Schön, D.A. (1978), “Organizational learning: A theory of action approach”, Addison Wesley, Reading.

Akkerman, S.F. and Bakker, A. (2011), "Boundary Crossing and Boundary Objects", Review of educational research, Vol. 81 No. 2, pp. 132-169. https://doi.org/10.3102/0034654311404435

Arnold, L. (2002), "Assessing professional behavior: yesterday, today, and tomorrow", Academic medicine, Vol. 77 No. 6, pp. 502-515.

Barki, H. and Hartwick, J. (2004), "Conceptualizing the construct of interpersonal conflict", International Journal of Conflict Management, Vol. 15 No. 3, pp. 216-244.

Blessing, L.T.M. and Chakrabarti, A. (2009), DRM, a Design Research Methodology, Springer, London.

Bradbury Huang, H. (2010), "What is good action research?" Action Research, Vol. 8 No. 1, pp. 93-109.

Boradkar, P. (2010), Designing things: a critical introduction to the culture of objects, Berg, Oxford, UK.

Casakin, H. and Goldschmidt, G. (1999), "Expertise and the use of visual analogy: implications for design education", Design Studies, Vol. 20 No. 2, pp. 153-175. https://doi.org/10.1016/S0142-694X(98)00032-5.

Carlile, P.R. (2002), "A pragmatic view of knowledge and boundaries: Boundary objects in new product development", Organization science, Vol. 13 No. 4, pp. 442-455. https://doi.org/10.1287/orsc.13.4.442.2953

Clark, P.G. (1997), "Values in health care professional socialization: Implications for geriatric education in interdisciplinary teamwork", The Gerontologist, Vol. 37 No. 4, pp. 441-451. https://doi.org/10.1093/geront/37.4.441

den Ouden, E. (2012), Innovation Design: Creating Value for People, Organizations and Society, SpringerVerlag, London. https://doi.org/10.1007/978-1-4471-2268-5

Friedman, B. and Hendry, D. (2012), "The envisioning cards: a toolkit for catalyzing humanistic and technical imaginations", CHI Conference on Human Factors in Computing Systems, Austin, Texas, 5-10 May 2012, pp. 1145-1148. https://doi.org/10.1145/2207676.2208562

Jehn, K.A. (1995), "A multimethod examination of the benefits and detriments of intragroup conflict", Administrative Science Quarterly, Vol. 40 No. 2, pp. 256-282. https://doi.org/10.2307/2393638

Jehn, K. A., Chadwick, C. and Thatcher, S. M. B. (1997), "To agree or not to agree: The effects of value congruence, individual demographic dissimilarity, and conflict on workgroup outcomes", International journal of conflict management, Vol. 8 No. 4, pp. 287-305. http://dx.doi.org/10.1108/eb022799

Kasser, T. and Ahuvia, A. (2002), "Materialistic values and well-being in business students", European Journal of Social Psychology, Vol. 32 No. 1, pp. 137-146. https://doi.org/10.1002/ejsp.85

Le Dantec, C. A. and Do, E. Y.-L. (2009), "The mechanisms of value transfer in design meetings", Design Studies, Vol. 30 No. 2, pp. 119-137. https://doi.org/10.1016/j.destud.2008.12.002

Lynn Fitzpatrick, R. (2007), “A literature review exploring values alignment as a proactive approach to conflict management", International Journal of Conflict Management, Vol. 18 No. 3, pp. 280-305. https://doi.org/10.1108/10444060710826007

Malle, B.F. (2004), How the Mind Explains Behavior: Folk Explanations, Meaning, and Social Interaction, MIT press.

Moon, J.A. (1999), Reflection in Learning \& Professional Development, Kogan Page, London, UK.

Rothkegel, D. (2012), "Innovation in Large Organizations: A matter of value and belief?", Design Research Society DRS, Bangkok, 1-4 July 2012, pp. 1617-1628.

Schön, D.A. (1983), The Reflective Practitioner : How Professionals Think in Action, Routledge, London.

Schwartz, S. (2012), "An Overview of the Schwartz Theory of Basic Values", Online Readings in Psychology and Culture, Vol. 2 No. 1. https://doi.org/10.9707/2307-0919.1116

Sheldon, K. M. and Kasser, T. (2001), "Goals, Congruence, and Positive Well-Being: New Empirical Support for Humanistic Theories", Journal of Humanistic Psychology, Vol. 41 No. 1, pp. 30-50. https://doi.org/10.1177/0022167801411004

Stappers, P.J. and Sanders, E.B.N. (2012), Convivial toolbox: Generative research for the front end of design, BIS Publishers, Amsterdam.

Sortheix, F. M., Dietrich, J., Chow, A. and Salmela-Aro, K. (2013), "The role of career values for work engagement during the transition to working life", Journal of Vocational Behavior, Vol. 83 No. 3, pp. 466-475. https://doi.org/10.1016/j.jvb.2013.07.003.

\section{ACKNOWLEDGMENTS}

We are grateful for the opportunity Jen Gijbels gave us to collaborate with the Fundamentals Academy and participate as coach in their new Designers Identity programme. We also would like to thank the 
trainees of the programme to participate in our research. Without their trust and honesty we could not have collected our requirements and continue working on a concept approach. We realize the client might come off as an unfriendly person, which he is not. His business minded stance is only representing a typical confrontation junior designers may experience when entering the work field. 